\title{
On the Present Situation of College English Translation Teaching in China and its Countermeasures
}

\author{
Xuming Shang \\ School of Foreign Languages \\ Xinyu University \\ Xinyu City, Jiangxi Province, China
}

\begin{abstract}
This paper analyzes the present situation existing in college English translation teaching. After analysis, the paper discusses the problems in the translation teaching and then put forward some countermeasures to change this situation.
\end{abstract}

Keywords-college $\quad$ English
countermeasures; present situation

\section{INTRODUCTION}

English teaching is a systematic project, the purpose of which is to cultivate student's overall ability to use English to communicate with people having a different cultural background. Students' performance in different English courses usually reflects our teaching results. English translation course is one of all the courses in English teaching and is listed as a compulsory English course in some colleges and universities. According to the response from the English learners, their feedback on translation level and aptitude testing, and the employers' feedback, many problems concerning the English translation teaching arose. In light of the learning attributes of the learners, Luo xuanmin divides the translation teaching into college English translation teaching and English major translation teaching. Presently, the focus of English translation teaching is on English major translation teaching, whereas the study of college English translation is often ignored. We will take a look at the present situation of college English translation teaching and put forward some countermeasures.

\section{The PRESENT Situation In COLLEGE ENGLiSH TRANSLATION TEACHING}

At present, the college English translation teaching is marginalized in English translation studies. This situation is demonstrated by the translators' debate about pedagogy of translation and pedagogical translation advanced by Jean Delisle in China. As for the above debate, the universal view is that the focus of pedagogy of translation is to impart translation skills and knowledge to learners with a view to cultivate professional translators whereas the pedagogical translation is regarded as an approach to foreign language teaching with an aim to help students master the language points and to improve their foreign language proficiency. It is obvious that the focuses of these two concepts are different from each other. However, one common view shared by teachers and researchers of foreign languages is that pedagogical translation refers to translation between Chinese and foreign languages in language teaching which puts low demand on the translation texts and is suitable for other forms of foreign language teaching except translation courses, whereas the pedagogy of translation, which takes translation teaching as its objective, has a relatively high demand on the translation texts. It is well known that pedagogical translation is often used in college English teaching and is seldom applied in the teaching of translation to English majors.

One direct outcome of the marginalization of pedagogical translation is the marginalization of college English translation teaching in translation teaching. Furthermore, translation teaching is also marginalized in college English teaching. We can discover this phenomenon in several aspects. First, as an outline to instruct and check college English teaching, the College English Teaching Syllabus doesn't put much emphasis translation teaching. For example, the College English Curriculum Requirements, which was designed by the Chinese Ministry of Education in 2007, focuses on students' comprehensive English applying abilities, especially students' listening and speaking abilities.

\section{Problems Existing In PRESENT College ENGLish TRANSLATION TEACHING}

The marginalization of translation teaching in college English teaching brings a lot of obvious problems to college English translation teaching. The first obvious problem is that the setting of translation courses is in an embarrassing situation. According to incomplete statistics, almost all the college English translation courses offered for non-English major students are set up as the public optional courses. In some colleges and universities, there aren't any translation theory and practice courses offered for non-English majors at all. The public optional nature of the translation course causes the translation teaching to be in a difficult situation. First, the length for studying this course is very short, and the lecture time for this course is seriously insufficient, which 
leads to the difficulty in fulfilling the teaching task. Affected by many factors, many colleges set rigid stipulations on the duration of public optional courses length which is regularly one semester with two class hours a week. This short period of time is insufficient to fulfill the teaching task for translation theory and practice courses. Under most circumstances, the main points of translation can be touched upon like a dragonfly skimming the surface of the water, the teaching results of which can be imagined. Secondly, in light of the importance of the translation theory and practice, a large number of students attend this course, which results in a large class which usually consists of two hundred to three hundred students. As a result, translation practices are not easy to be conducted and the quality of the translation teaching can not be ensured easily. Lastly, because of the large number of students who taking this course, the various levels of the English and Chinese of the students, and the fact that many students take this course just for credits, the interaction between the teacher and the students is very difficult to be conducted.

As mentioned above, the College English Syllabus just put some requirements on students' translation ability, and it doesn't set an overall teaching plan for this course. At present, the translation teaching courses offered to nonEnglish majors lack coordination. Even worse, teachers who are engaged in translation theory studies and translation practices in the same colleges also lack communication, not to mention the connections and communications between teachers engaged in translation teaching and studies from different colleges and universities. Although the College English Curriculum Requirements sets different requirements on students' translation ability in the three levels of college English teaching consisting of general requirements, high requirements and higher requirements, it doesn't give specific instructions on the teaching contents and methods for different levels of students, which causes cohesion problems between teaching contents of different levels. This greatly affects the teaching quality, which consequently influences the attaining of teaching objectives. At present, the most common translation teaching method is the one used in traditional college English teaching. This teaching method takes the teacher as the center in the course of teaching, with the imparting of translation knowledge from the teaching to the students and the focus of which is the ultimate quality of students' translation. As a result, the cooperation and communication between the teacher and the students are limited, and the necessary cooperation and communication between students are also rare, which results in the difficulty of students' giving full play to their subjectivity in class. Moreover, because of large number of students taking the translation course, the teacher cannot give feedback to each student of the class. Accordingly, it is very difficult for students to find out their own shortages and weakness, which is not conducive to the improvement of their translation ability. In addition, the traditional college English translation teaching method lays one-sided emphasis on the teaching of language knowledge and translation knowledge and neglect the training of translation skills. This method seldom emphasizes the cultivation of students' initiatives and translation practice ability.
There is hardly any national translation textbook for nonEnglish majors. According to the statistics by Li Defeng, there are more than three hundred translation textbooks, translation guidebooks and translation handbooks published over the past few years, most of which are in low quality and have lots of errors and mistakes. According to our findings, many college English textbooks recommended by the ministry of education hardly touch upon translation theory and skills, let alone systematic introduction and explanation them. Most translation textbooks adopted in many colleges and universities are outdated. Even the newly published translation textbooks lack originality in its contents and forms, and most of them are the same in essentials while differing in minor points. Translation teachers usually use several textbooks at the same time so that they can piece together the teaching contents from those textbooks. Although exercises are designed in each unit, these translation exercises are devised to review and strengthen the related language points such as vocabulary, phrases, sentence patterns, syntactic structures and so on. Moreover, the examples adopted in the translation books are selected form ordinary literary works. They seldom or don't touch upon foreign documents, business, medicine, science and technology and so on. As we know, the requirements and emphasis of the translation of literary works are different from those of non-literary works. The text of literary works has the emotional functions and aesthetic functions as well as informative functions and puts its emphasis on the beauty and magnificence of the language. In contrast, the text of a non-literary is to transmit information and the translation of such texts should be accurate, natural and logical. In a diversified international environment, the translation ability should also be diversified.

Besides, most college students lack the basic crossculture knowledge. Though this problem is demonstrated by students, it reflects the problem existing in teaching designing. Students' extracurricular reading is small and narrow. They don't pay much attention on extracurricular reading of English materials. They just focus on curricular contents and strengthen their listening and speaking ability. This inevitably results in their difficulty in increasing their vocabulary. Because of their narrow scope of knowledge, most students are short of cultural cultivation. Nevertheless, the difficulty existing in translation is the awareness of cultural differences between China and the western world. Since most students can only translate words and sentences, they can not translate the background information such as English history, culture and religion that exists in the source English language accurately. The American translation theorist Eugene Nida points out: "Translation is the communication between two cultures. As for a truly successful translator, to be familiar with two cultures is even more important than to master two languages, because words and phrases are meaningful only in its cultural background in which it plays a role." Therefore, cross-culture cultivation should be a key point in students' translation courses. 


\section{COUNTERMEASURES}

Based on the above analysis, we suggest the following countermeasures to improve the college English translation teaching.

\section{A. To Set Translation Syllabus According to the Training Objective}

Although the College English Curriculum Requirements puts forward three different levels of English translation ability, we should set targeted syllabuses according to the training objectives of different talents. The syllabus should points clearly that translation teaching refers to a kind specialty teaching which is offered for students with corresponding English proficiency in order to cultivate students' translation ability and to realize the transformation from English study to English use. The course designing in the syllabus should fit the needs of the society which contains both translation texts of literary works and those of practical writing. By doing so, we can cultivate comprehensive foreign languages talents who are proficient in foreign languages and have professional knowledge. Enough teaching hours should be also guaranteed. Translation is a kind of skill that can only be acquired through large amount of practice. Good results of any subjects should be obtained through enough teaching hours. Translation is a course which takes practice as its basis, thus needing enough teaching hours.

\section{B. To Reform the Present Textbooks and Course Designing}

Textbooks are the important carriers of teaching contents. To change the outdated and unitary condition of present textbooks, we should carry out a reform of the present textbooks. In order to adapt themselves to the modern time, the contents of the textbooks should be close to society and the textbooks should take true materials and examples as their contents, such as articles in newspapers and periodicals, practical trade and business writings, common or newlymade legal provisions and documents of the United Nations or governments. The practical applicability of the textbooks should be highlighted. Course design should be also reformed. At present, there are few teaching hours for translation which is a common phenomenon. This can be compensated by integration of intensive teaching in classes and extracurricular activities. Teachers can hold translation lectures irregularly or offer translation-related optional courses. The courses including translation skills and comparison between Chinese and English can be offered to students at the elementary stage so that students can master the basic principles in translation. At the advanced stage, the courses of western culture, business negotiation, culture and translation, and cross-culture communication can be offered to students. In addition, with the modern information technology, the multi-perspectives and three-dimensional extracurricular textbooks with rich contents which integrate with traditional textbooks can also be developed.

\section{To Innovate the Teaching Method Unremittingly and to Increase the Proportion of Case Teaching in the Whole Process of Translation Teaching}

A rational teaching mode should be demonstrated by the classroom teaching with the students as the center and can arouse students' initiatives and enthusiasm. Communicative teaching method can be added to the traditional teaching method. The communicative teaching method is interactive teaching between the teacher and the students which takes the students as the center of teaching. Bidirectional and multidirectional communicative translation teaching method should also be adopted. By doing so, the communications between the teacher and students, students, students and the teacher can be realized so that the dynamic integration of learning and teaching can also be attained. Lots of translation teaching experiences show that the lecture-comment teaching method has relatively good results. In the course of translation teaching, commenting on the translation examples is an important link. It plays an irreplaceable role in helping students understand the contents of the translation materials, cultivating students' problem-analyzing and solving ability, and helping students draw extensive knowledge from the translation materials. The development of students' problem analyzing and solving ability depends not only on teacher's lecture and students' listening but on students' own discussion and analysis under the instruction of the teachers. In this course, teachers should constantly search and reorganize the typical translation exercises so that the teaching has a definite object in view. Presently, our society needs more practical translation talents than before, so the proportion of professional teaching in the traditional academic teaching should be increased in translation teaching. Knowledge-centered teaching method should be transformed into knowledge-imparting plus abilitydeveloping teaching method. The proportion of case analysis such as the analysis of translation of public English signs, business letters translation and foreign publicity translation in the translation teaching should also be increased. The adjustment of the proportion of teaching and learning involves the reformation of textbooks. The traditional translation teaching method with teachers' reading what the textbook says is far from being enough. Teachers who are engaged in translation teaching should collect and accumulate a large number of representative translation cases which are close to the society and the time during their teaching and translation practices. These translation cases should be used in their teaching and are students' indispensable learning practices in their study.

\section{To Improve the Structure of the Teaching Staff}

Firstly, the improvement of the professional ability of the specialized teachers should be valued. Among the foreign language teachers, few are specialized in translation teaching. Some of them switched to the teaching and research of translation from the research of linguistics or literature. They should strengthen their study and research of the translation history of Chinese and western countries, translation theory, and the skills of translation and interpretation. At the same time, these teachers' Chinese level is relatively low because of their long time of involvement in English teaching. The 
teachers who are engaged in translation teaching should have a relatively high Chinese proficiency and have a general knowledge of cultures of different countries in the world and other subjects. Translation is a strong practical subject. We should establish the system of inviting visiting professors to give lectures on translation to students. According to different teaching objectives, translators who have long been engaged in translation and interpretation and have abundant practical experiences should be invited to conduct case teaching. Through their lectures, translation teaching can go out of the classroom, thus cultivating students' practical ability. With the quickening of the opening-up to the outside world in China and the urgent demand for various talents, education units at various levels should highlight the task of establishing a translation team with high level and high quality and conduct translation training for translation teachers systematically.

\section{E. To Improve Students' Comprehensive Language Ability and to Strengthen Their Cross-Culture Awareness}

In order to improve their comprehensive language ability, students should not only enlarge their vocabulary, but also strengthen their learning and mastering of translation knowledge and skills. Students' study of language and culture backgrounds and the contextual meanings of Chinese and English languages should be stressed so that students can have a deep understanding of the cultural differences between Chinese and English languages. Practice shows that this the only way which must be passed to improve students' translation ability. Translation means one's bilingual competence. Traditional translation teaching focuses only on cultivating students' English language ability, but neglects the improvement of students' Chinese proficiency. This results in students' far-fetched Chinese versions or the Europeanization of their sentences, which do not conform to Chinese writing style and reading habits. Therefore, enough class hours should be guaranteed and special textbooks should be provided to engage students in English-Chinese translation training.

The acquisition of cultural background knowledge is a process of studying and accumulation. Therefore, cultural introduction to students and the cultivation of students' cultural awareness and cultural attainment should be emphasized in translation teaching. We should pay attention to the cultural differences between Chinese and English demonstrated in the two languages and make students be familiar with the geographical environment, customs and habits, religious beliefs and historical stories on which the formation and development of English language relies. Teachers should encourage students to enlarge their knowledge of language and culture in the target language in their extracurricular time, recommend classic English and American literary works and newspapers and periodicals to students consciously, and encourage students to view lots of original movies from USA and UK, which will be conducive to the cultivation of cross-culture awareness.

The adoption of culture teaching into translation teaching is a general trend. At present, the study of language has changed from the mere research of characters into the researches of language and culture. The English translation teaching should embody this change, applying the up-dated research findings of language into the classroom teaching and make students realize that language translation is a kind of cultural activity. Translation is essentially a kind of crossculture communication. The understanding of different languages is closely related to the regional culture and historical background in which those languages are. Furthermore, Chinese culture belongs to humanity culture, whereas the western culture belongs to science culture. The differences between Chinese culture and western culture are shown by languages in different poses and with different expressions. To explain these differences to the students in the course of translation teaching can help students see clearly the culture information carried by the languages, which can not only enrich the student's knowledge of cultural backgrounds but also strengthen their sensibility to cultural differences, thus reducing the possibility of culture shock of the students and effectively coping with the problem of different cultures in translation which will accordingly improve the quality of translation.

\section{CONCLUSION}

From the above analysis, we can see that the current translation teaching is not perfect. Problems demonstrated by students' translation practices also reflect the defect in our course design and reveal the flaw and drawbacks of the present system of translation teaching. With the rapid development of globalization and information and Chinese increasing contact with foreign countries, the Chinese translation industry is growing up. It puts an increasingly higher demand on translation talents. To deepen the translation teaching reform becomes an urgent task to cultivate the comprehensive and practical translation talents. We should conduct bold exploration and research in teaching ideas, course design, updating textbooks, teaching organization and put them into practice so that the translation teaching system can meet the requirements of China's development and opening-up to the outside world.

\section{REFERENCES}

[1] Yange Chen, "Reflections on pedagogical translation and pedagogy of translation in college English," in Foreign Languages and Their Teaching, 2002(7):42-44.

[2] Defeng Li, Mu Hu, "Learners-centered Translation Course Design", Journal of Foreign Languages, 2006(2):59-62.

[3] Xuanmin Luo, "On the teaching of translation in China: problems and perspectives," Chinese Translators Journal, 2002(4):56-58.

[4] Lei Mu, "Ways for the development of translation teaching," Chinese Translators Journal, 2004(5):25-26.

[5] Jianbo Pei, "On the ten negative influence of pdegogical translation on pedagogy," Higher Education Forum, 2003(1):104-108.

[6] Hong Xiao, "The application of translation workshop in translation teaching," Journal of Sichuan International Studies University, 2005(1):139-142.

[7] Meiping Zhang, "Development of translation skills and college English teaching," Chinese Science and Technology Translators Journal, 2005(2):32-35.

[8] Youyi Huang, "Society needs more practical translation talents," Chinese Translators Journal, 2007(1):47-48 
[9] Heping Liu, "On the principles and methods of undergraduate translation teaching," Chinese Translators Journal, 2009(6):34-41. 